REVISTA ARA N6 . VOLUME 6 . OUTONO+INVERNO 2019 • GRUPO MUSEU/PATRIMÔNIO FAU-USP

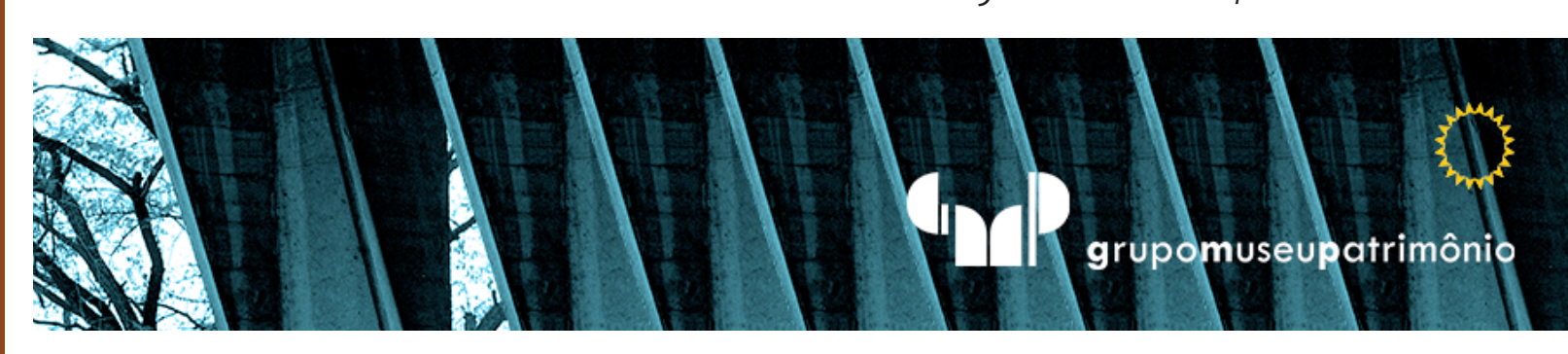

\title{
Curadoria: arte de narrar
}

Curadora: arte de narrar

Curator: art of narrating

Maria Cecilia França Lourenço

Professora Titular Sênior, Faculdade de Arquitetura e Urbanismo/USP, Editora da Revista ARA. São Paulo, BRA. e-mail revistarafau@usp.br 


\section{Resumo}

A Revista ARA FAU USP expõe neste número o esforço integrado entre membros de Conselho Editorial, Grupo Museu/Patrimônio, autores, que se submeteram e foram selecionados por Pareceristas, desta maneira gerando elo bastante singular e composto por estudiosos da área. 0 tema escolhido para esta edição - Curadoria, Argumento, Fricção - reside em analisa Congregam-se textos inéditos em diálogo com conteúdos controversos neste período, a demandar debates aqui apresentados.

Palavras-Chave: Curadoria. Argumento. Fricção. Estudos. Editorial.

\section{Resumen}

La Revista ARA FAU USP expone en este esfuerzo integrado entre los miembros de Junta, Museo de la herencia Grupo Editorial, autores, presentadas y fueron seleccionados por expertos, formando asi un enlace muy singular y compuesto de expertos en el área. El tema elegido para esta edición-Curador, Argumento, Fricción-reside en el análisis de numerosos experimentos y variaciones de fuentes diferentes. Estudios no publicados se congregan en diálogo con

contenido controvertido en este período, para exigir la discusión presentada aqui.

\section{INTRODUÇÃO}

Palavras-Clave: Curador. Argumento. Fricción. Estudios. Editorial.

\section{Abstract}

The journal ARA FAU USP exposes in this integrated effort between members of Editorial Board, research Group Museum/Heritage, authors, papers submitted and selected by Experts, thus forming a very singular link composed by scholars in the area. The theme chosen for this edition - Curator, Argument, Friction lies on analyzing numerous experiments and variations from different sources. lies on analyzing numerous experiments and variations from different sources. It congregates unpublished studies in dialogue with
this time, to demand discussions presented here.

Keywords: Curator. Argument. Friction. Studies. Editoria

Cada manhã recebemos notícias de todo o mundo. E, no entanto, somos pobres em histórias surpreendentes. A razão é que os fatos já nos chegam acompanhados de explicações. Em outras palavras: quase nada do que acontece está a serviço da narrativa, e quase tudo está a serviço da informação. Metade da arte narrativa está em evitar explicações. Walter Benjamin

- sta edição da Revista ARA FAU USP versa sobre Curadoria, Argumento, Friçção e exibe o quanto se torna profícuo optar-se por compartilhamento entre alteridades, seja em matérias seja em autores. Constitui uma espécie de fabulação sobre ensaios visuais engendrados em formas e questões expositivas. Assunto este muitas vezes ventilado por 
informes e texto para divulgação feitos pelos próprios interessados, no entanto distante do que Walter Benjamin nomeia por narrativas ${ }^{1}$.

Não se busca, portanto, formular algo avizinhado de descrição, fato, explicação ou justificativa, mas sim ressaltar a proximidade com esse fazer, aliada à possibilidade de espelhar criticamente inquietações e caminhos antes trilhados, peculiaridades presentes nos estudos e problematizações aqui criados. A edição engloba muitos falares e saberes, em época lamentavelmente marcada pelo oposto: banalização da vida, destituição da escola em seu papel de formar, transformar e harmonizar diferenças ${ }^{2}$, ao lado de se opor à polarização entre atitudes extremas.

A Revista ARA labora na contramão dessas posições preconceituosas e procura aprimorar, alargar o campo cultural, incidir em diálogos para além de muros e certezas dogmáticas, que enlameiam expectativas para uma cultura digna. Ao desbordar fronteiras, em esforço para superar limites geográficos e ideológicos, o conjunto expõe autores em variado estágio e performance acadêmica. Constatam-se empenho, atualização e mérito, longe, portanto, do cenário visto em áreas similares, não raro vazado pelo trivial e raso.

O resultado descortina horizontes, neste momento de vaga conservacionista, que garante privilégios para os já detentores destes. Inúmeras instituições diferentemente vêm cumprindo papel crítico ao formular conhecimento, dar guarida à dúvida e, acompanhando Tzvetan Todorov, no lugar de tentar boa interpretação visam "[...] compreender, e se possível manter, o complexo e o plural” (Todorov, 2014, p. 26).

${ }^{1}$ A diferenciação entre informação e narrativa coaduna-se a aquela formulada por Benjamin quando discorre, em edição datada em 1936, no célebre texto sobre a obra do escritor russo, Nikolai Lescov (1831-95) (1994.p.203).

${ }^{2}$ Levantamento recente do Tribunal de Contas do Município paulistano informa que além de metade $(45,4 \%)$ tinha disciplinas sem professores. Isto na maior cidade do país. Segundo publicação no Diário Oficial da União, em 13 de março, 2019 o atual presidente cortou uma série de cargos públicos, sendo $65 \%$ na área da educação, como se noticiou amplamente.
Em especial as universidades, de modo geral, resistem e procuram desvelar papel ímpar ensejado pela cultura extensionista, quando se propõem a ouvir, mais do que falar, para entrelaçar querelas e reforçar câmbios, como se constata na presente edição da Revista ARA. Esta acolhe com largueza análises sobre a cultura contemporânea, a formar no futuro a História destes tempos. Vivencia-se a premência cotidiana em se vincular o tripé fundante de universidades, a saber - a ligação entre ensino, pesquisa e extensão, nesta hora algo esquecido por rejeição contundente às trocas.

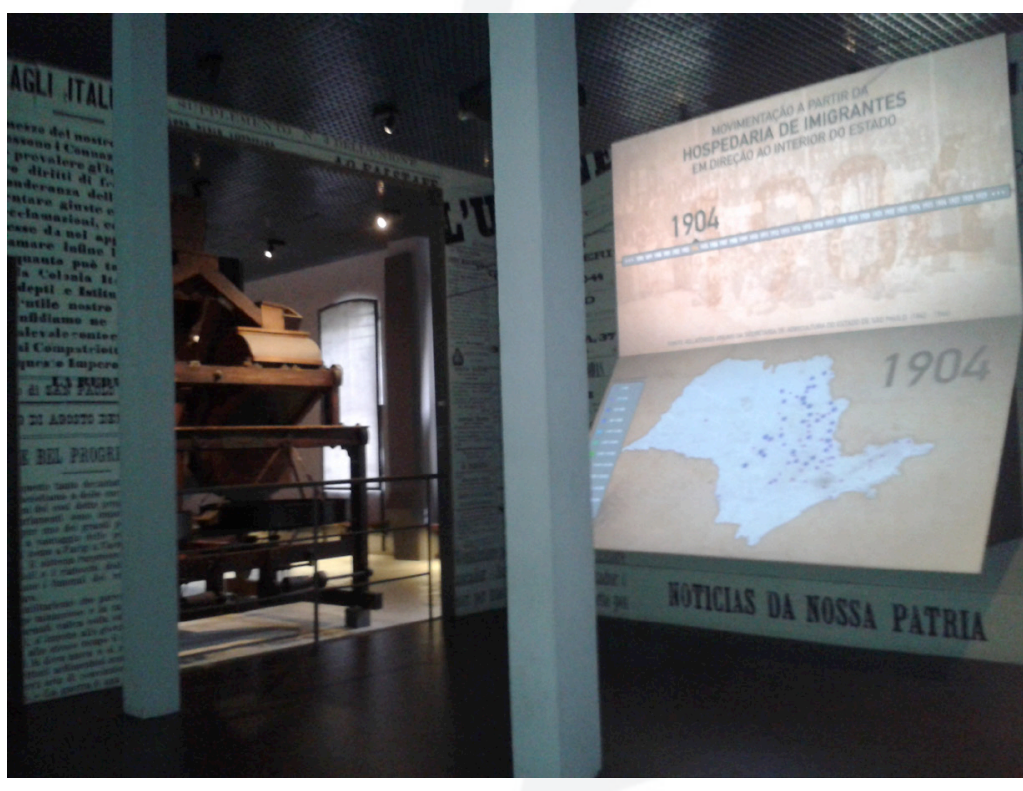

Figura 1 Museu da Imigração do Estado de São Paulo. Visita Técnica à Exposição com Grupo Museu/Patrimônio FAU USP em 25.02. 2016. Foto $A$.

Formulam-se questionamentos que reposicionam e reafirmam o pleito por seriedade no trato investigativo da cultura para formar cidadãos abertos, portadores de valores plurais, generosos, gregários e em correspondência com amplos estratos sociais. Dá as costas às abordagens correntes sedentas apenas por lucro financeiro, mercado, projeção pública e atraídas pelo espetáculo, a afastar de protagonismo e defesa de valores, usuais neste tempo.

A seleção de objetos curatoriais em áreas como artes, história e costumes transborda nessa direção, notando desvios, a citar, processos espaciais para 
cultura contemporânea, espelho e olho curatorial, artista-curador, curador institucional, diplomata-curador, grupo curatorial, curador independente, curadoria compartilhada, curadoria de gênero, curadoria autoral, controle tecnológico, espaço urbano, negociações curatoriais, heteretopia de imagens, dispositivos e processo de escolhas curatoriais étnicas.

Observe-se que autores registram variado debate sobre a narratividade embasada por meio de pensadores, para examinar a organização de formas, dispostas ao olhar. Vale ressaltar, além de Walter Benjamin, a existência de conceitos sendo explanados em variadas áreas, seletas pela ligação com cada objeto escolhido para exame. Entre estes cumpre lembrar, Giorgio Agamben, Marc Augé, Hans Belting, Pierre Bourdieu, Anne Cauquelin, Guy Débord, Michel de Certeau, Arthur Danto, Hal Foster, Michel Foucault, Maurice Halbwachs, Stuart Hall, Octávio lanni, Hans Robert Jauss, Jacques Le Goff, Octávio Paz, Milton Santos.

Englobam recortes contemporâneos, entre tantos, ampliação das personagens a partilhar decisões setoriais; deslocamento e fricção de significados de obras antes reveladas em outros arranjos; expor o invisivel; narrativas silenciadas; mundialização versus globalização, contaminação entre antigas fronteiras profissionais; seleção de formas e objetivação de valores; política e escolhas; formas marcadas por trocas com espectadores em variado espectro; aparato e tecnologias institucionais; memória e cultura digitais; crítica aos modos consagrados para mediação com visitante; dispositivos exposicionais; o papel de redes digitais; momentos extremos e luto.

Abrangem-se clássicos a analisar curadoria expositiva e sublinhem-se alguns citados nos trabalhos nesta oportunidade documentados: Jérôme Glicenstein, Lucy Lippard, Débora Meijers, Hans Ulrich Obrist, Brian O’Doherty, Nicola Trezzi. Outro fato a ser grifado se observa na menção a textos curatoriais e não apenas no país, em grande parte para criticar, superando o simples ilustrar. Cabe lembrar a importância de numerosos estudos em que se avalia história museica-exposicional em dissertações e teses, boa parte delas presente em arquivos digitais de universidades, passíveis de acesso e aqui incluídos.

Em nome desse conjunto incomum convido os leitores a deleitar-se com as valiosas investigações, inseridas nesta publicação. Agradeço aos colegas envolvidos, repito composto por Conselho Editorial, Grupo Museu/Patrimônio - GMP, funcionários da FAU USP, autores, que enviaram e foram selecionados, pareceristas. Acrescento aqueles que responderam ao Edital, entretanto na análise chamada "à cega", vale dizer sem identificação e por ao menos dois estudiosos da área, designados pelo Conselho Editorial avaliaram que a submissão não cumpriu integralmente o proposto nesta edição e, por certo, nos veremos todos em outra oportunidade.

Ciça. Outono 2019

\section{REFERÊNCIAS BIBLIOGRÁFICAS}

Benjamin, Walter. O narrador: consideraçōes sobre a obra de Nicolai Leskov. In: Magia e Técnica: arte e política. Obras escolhidas. Volume I. São Paulo: Brasiliense; 1994.

Todorov, Tzvetan. Simbolismo e interpretação. São Paulo: Editora Unesp; 2014 